\section{Gategory}

Synthesis of Materials and Unnatural Products

\section{Key words}

\section{fullerenes}

regioselectivity

n-type materials

Y. MATSUO,*A. IWAShitA, Y. ABE, C.-Z. LI, K. MATSUO, M. HAShiguChi, E. NAKAMURA* (JAPAN SCIENCE AND TECHNOLOGY AGENCY, TOKYO AND THE UNIVERSITY OF TOKYO, JAPAN)

Regioselective Synthesis of 1,4-Di(organo)[60]fullerenes through DMF-assisted Monoaddition of Silylmethyl Grignard Reagents and Subsequent Alkylation Reaction J. Am. Chem. Soc. 2008, 130, 15429-15436.

\title{
Efficient Regioselective 1,4-Substitution of [60]Fullerenes
}

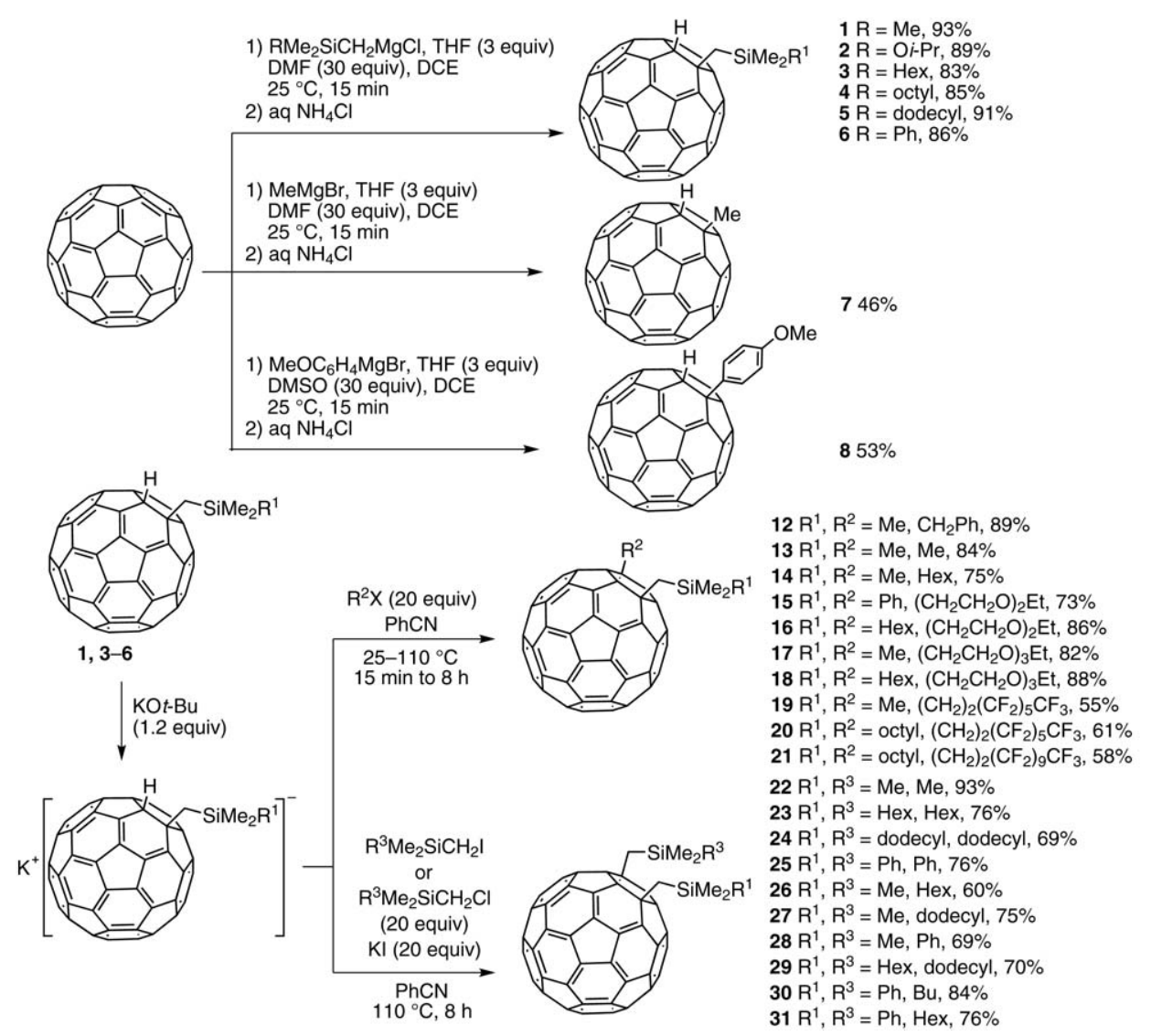

Significance: The authors report a two-step regioselective synthesis of 1,4-di(organo)[60]fullerenes. In the first step, DMF-assisted monoaddition of silylmethyl Grignard reagent to [60]fullerenes produces (organo)(hydro)[60]fullerenes. Deprotonation and alkylation in the second step generates di(organo)[60]fullerenes with various functional groups, whose crystal structures, electrochemical and thermal properties have been studied.
Comment: The synthetic difficulties of 1,4-substituted $58 \pi$-electron [60]fullerenes make them less explored than their 1,2-substituted counterparts such as PCBM. This efficient approach with high regioselectivity, simple starting materials and easy procedures may lead to new opportunities to the research on fullerene based n-type materials.

SYNFACTS Contributors: Timothy M. Swager, Fei Wang 